\title{
Exploration and Practice of SE-CDIO Educational Pattern
}

\author{
Liu Jian-Bin ${ }^{\mathrm{a},{ }^{* 1}}$, Yang Zhi-Yun ${ }^{\mathrm{b},{ }^{* 2}}$ \\ ${ }^{a}$ Department of Software Engineering, Beijing Information Science and Technology University, Beijing, China \\ ${ }^{b}$ School of Science, Beijing Information Science and Technology University, Beijing, China
}

\begin{abstract}
Taking the requirement and the education goal of software engineering application talented person as guidance, referring to advanced ideas of the international CDIO higher engineering education, combining realities of software engineering undergraduate educates, this paper presents that innovative SE-CDIO pattern for the cultivation of software engineers is developed and implemented in curriculum system, practice teaching and other respects in the software engineering undergraduate specialty of Beijing Information Science \& Technology University. Through designing SE-CDIO application personnel cultivation program for software engineering undergraduates, carrying out educational reform practice positively, we raise diligently the quality of software engineering undergraduates who conforms to the discipline and social development need, at the same time promote discipline and specialized development.
\end{abstract}

Index Terms: Software Engineering; CDIO; Undergraduate Cultivation; Educational and Pedagogical Pattern

(C) 2012 Published by MECS Publisher. Selection and/or peer review under responsibility of the International Conference on E-Business System and Education Technology

\section{Introduction}

In recent years, China's higher engineering education has made considerable progress. Above $30 \%$ university's enrolled students are studying engineering. It develops direct promotion effect to the national economy by training massive graduates in this field. However, there are many problems in the whole present engineering education such as heavy theory and light practice, as well as the theory and practice, the teaching and reality, knowledge instruction and ability quality raise coming apart. The main performances are as follows. Curriculums studied by engineering students are limited, and we pay great attention to discipline knowledge instructions. But it is weaker in individual ability, professional quality, interpersonal competence and system design construction capacity cultivation. Specially, students lack training about communication and expression, team cooperation and project practical experience, and educating on good faith, occupational ethics and responsibility, legal consciousness and so on. Graduates adapt the modern enterprise's demands with difficulty. The educational pattern of "heavy theory light practice" has limited students' innovation and the practical ability development seriously. The quality of personnel training and social demand gap compared. So the higher engineering educational reform in China is imperative.

\footnotetext{
* Corresponding author:

| E-mail address: ${ }^{* 1}$ ljb@ @istu.edn.cn; ${ }^{* 2} 20061570 @$ bistu.edn.cn
} 
In today's information society, software occupies an important position and role, and the industry becomes one of pillar industries. In order to adapt our economic structure strategic readjustment, the country has introduced a series of encouragement policies to support software industry and software engineer training leap frog development since 2000. We have set up 36 state-level demonstrative software institutes, ascertain software engineering as the new specialty which gives priority to development, and request various universities to train the high quality software engineering talented person for the country, so that promoting the development of the software industry in China. Under this background, many domestic universities have opened the software engineering specialty one after another. The discipline and specialized construction got a quick start. At present, our software engineering education obtained great development. But the contradiction between growing capable software person demand in information society and education supplies insufficient, specially the high quality professional education supplies serious insufficient, has become an important problem which the education development faces. With software engineering discipline increasingly mature, the original education pattern already could not adapt the discipline development request and the engineer training actual need. Therefore the explorations of education pattern which suit to the software engineering discipline development is very important, and the reform is urgent and necessary.

$\mathrm{CDIO}$ [1] (Conceive-Design-Implement-Operate ), an international engineering education standard, is formulated by International engineering education cooperation organization CDIO committee. The organization is initiated by American Massachusetts Institute of Technology, Royal Institute of Technology, four universities. Its syllabus meets requirements of engineering education in North America, Europe and other western countries, as well as other Washington agreement country professional engineer organizes. CDIO described development and deployment process of product and the system life cycle as the context of engineering education. It is a kind of educational reform framework and universality engineer education pattern, which resolves engineering education problems most systematically and comprehensively. The pattern has obtained successful application in different type, different level's engineering colleges' and universities' aviation, machinery, electronic information, applied physics and industrial design and so on. It is not only successfully applied in North America, Europe, South Africa, Asia, etc, but also has an important impact on global engineering education. The basic philosophy of CDIO is that we devise, design and realize according to reality, as well as utilize in society finally. And its points focus on innovation ability and practice ability. Based on foundation, CDIO concept takes the CDIO development life cycle process of the system and product as the carrier. The core courses' study is organized regarding the project. The disciplines support mutually and relate with each other, and interweave highly with system design construction. Besides emphasis on technology base teaching, it specially emphasizes students are the protagonists and main bodies in development process of systems and products. We also should carry out active learning, exploratory learning and cooperative learning in the classroom, the laboratory or more modern learning places. Students will obtain comprehensive training on the scientific knowledge, individual ability and professional skill, interpersonal ability as well as system construction and regulative ability in practice[2].

$\mathrm{CDIO}$, as a new undergraduate education framework, is designed for fostering next generation engineers. It obtains widely approves from numerous educational, industrial figures and organizations all over the world. Relevant research results emerge unceasingly, which have been symbolic achievements in international engineering teaching reform. Now CDIO promotion has achieved obvious effect in western universities. It is a kind of engineering education concept to cultivate person's ability and quality comprehensively. It can display person's various potential fully, and guarantee that graduate possess professional skill, professional quality, as well as lifelong learning and the hoisting capacity. At present the CDIO International Organization has developed into the international engineering education cooperative organization, including US, Britain, Europe, Asia and Pacific Ocean and several dozens of various universities. In January, 2004, the organization proposed 12 standards [1], which will be the international engineering educational reform criterion, implementation guide.

The exploration and practice of software engineering personnel fostering pattern, conforming to the international engineering education standards and our country national conditions, is the foundation of high 
grade discipline construction, specialized construction and personnel training. It has important practical significance to improve the level of software engineering education and teaching quality, cultivation of application-oriented software engineering professionals. And that makes the software engineering teaching more advanced, systematic and standardizing, causes engineering students obtain professional certification and meet the practical work needs.

\section{Reform Ideas and Goals}

According to CDIO engineering education idea, in software engineering discipline teaching, we should take the software development project as a background, combine the software engineering discipline knowledge, software's construction process with the CDIO education idea, explore and implement the SE-CDIO (Software Engineering-CDIO ) cultivation mode, thus raise high quality software engineer in line with international standards and our national conditions. Therefore, we need to refer to CDIO engineering education outline and software engineering professional education to carry out one whole set of reform. It is meaning that we shall systematically plan and transform raising program, curriculum syllabi, teaching methods, practice teaching contents and system essential factors.

Since 2006, according to international education engineering CDIO outline standards and requirements of the IEEE-SE2004, the software engineering department in Beijing Information Science \& Technology University has actively explored software engineering SE-CDIO education pattern. We carry out a new SECDIO program from 2008. We pay great attention to basic concept, as well as strengthen active learning, problem-based learnin[3], cooperative learning and exploratory learning. Reforming effort to improve the teaching level has been made as follow: Putting ""learning in doing" and "project task driven" into practice is a good method of strengthening theory and practice union and ability cultivation. Simultaneously, we carry on educational reform actively, improve teaching method unceasingly, update teaching contents, improve teaching conditions, strengthen teacher troop construction. At the same time, we use modern teaching means to develop CAI (Computer Aided Instruction) and audio-visual teaching actively, motivate students' active learning enthusiasm, develop teaching websites and CAI courseware, create students active learning supportive environment, and establish student productive practice bases.

In teaching idea renewal, we set up cultivating students' innovation consciousness, team cooperation spirit and style of theory and practice to the purpose. And we pay special attention to and strengthen engineering practice ability, synergy and professional skill comprehensive training. By introduction of advanced international CDIO teaching idea, we combined with the practice of software engineering specialized reality. The life cycle of software system development and deployment is determined as the software engineering education background, and software design project as carrier and trunk. The mode, project practice courses can drive learning of related core professional theory courses, develops attributes and skill training. Thus students will engage in active learning, exploratory learning and cooperative learning with practical problems. While their professional knowledge learning and knowledge application skills training will be more targeted and effective.

The mentality and localization of reform is that we refer to the advanced idea of the international CDIO higher engineering education, combine with our software engineering undergraduate education practice, carry out educational reform comprehensively to the software engineering specialty, and propose SE-CDIO education pattern, an innovative software engineering teaching and learning mode. It takes occupational ethics and good faith as foundations, and combines features of software engineering undergraduate education with the CDIO framework organically. The target is to cultivate high quality software engineers. The main content is that the point of software engineering education is the vocational ethics. Professional foundation is set up by the CDIO process. SE - CDIO lays more stress on cultivating project application ability, team cooperation communication ability, engineering technology studying independently and problem definition and solution capacity [4], as well as system regulation ability, self-learning abilities comprehensively in the science and technology, individual and specialized quality, interpersonal ability as well as system design and construction, 
etc. Thus we can raise high quality application software engineers with ability of lifelong learning at undergraduate level.

Guiding by software engineering professional demand, referencing to international advanced CDIO engineering education idea and standard, combining with our national conditions and software engineering undergraduate education characteristics, we carry on the full-scale reform in talent training scheme, curriculum system, teaching modes and methods, teaching contents, teaching links, teacher training and use and so on. Through the teaching and learning reform and key specialty construction, software engineering undergraduate specialty of Beijing Information Science \& Technology University is becoming a distinctive fostering base for high quality software engineers.

\section{SE - CDIO Cultivation Plan}

SE-CDIO cultivation plan is the programmatic document, which embodies and implements the SE-CDIO teaching and learning mode. Its features manifest in training objectives, professional characteristics, and curriculum system and progress arrangement.

The training target of high quality software engineer is to cultivate a batch of software engineering technicians and managerial personnel who have abundant engineering science foundation, creativity and systematic thinking ability, multi-disciplinary backgrounds and international vision, outstanding management and communication ability, team spirit, professional moral responsibility and legal consciousness. To achieve this goal, we should educate and cultivate student systematically and roundly in basic courses, analytical ability, creative and design ability, communication cooperation ability, leadership, professional morality, language ability and so on. Combining with application-oriented school localization and teaching reality of software engineering, we determined the training goal of this professional. The goal is to raise senior engineering applied talents who can adapt to the development of the computer software industry. At the same time, the person should possess good comprehensive attributes and professional ethics, master solid software elementary knowledge and software development skills, as well as have strong software design construction and testing ability, team cooperation ability, analysis and solving problem ability, communication and coordination ability and lifelong learning ability.

Professional design manifests in the teaching goal and cultivating mode. In the teaching goal, we combine with different discipline knowledge, taking comprehensive quality raising as the goal. At the same time, to adapt to the development of technology and social changes, we synthesize activities inside and outside classes, paying attention to professional morality, professional skills, interpersonal skills and system development ability, and strengthening professional practice and knowledge. In the cultivating mode, by introducing international advanced CDIO engineering education framework, we take raising individual vocational skill (including practical ability and lifelong learning capability), team ability as well as system construction and control adaptive ability as the essential target. And on basis of emphasizing integrity, professional morality and responsibility, we implement SE-CDIO mode. The mode takes engineering development life cycle as the carrier, oriented to practical and exploratory software engineering design.

In curriculum aspect, we introduced software engineering introduction and professional practice courses to stimulate student's seeking knowledge interest and establishing engineering concept and professional preliminary understanding. We adjustment convention subjects according to discipline knowledge system, and pay attention to integrate, so that make them links up and fuses mutually. Meanwhile, we show students multidisciplinary knowledge the software engineer needed, and the correlation and comprehensive application of knowledge. Through more basic course setting, student will lay a solid foundation. Simultaneously, the new program pays attention to raising integrity, professional ethical and legal consciousness, and offer "software engineers profession morality and responsibility" course.

In teaching schedule and distribution, we refer to the present procedure and experience of overseas same type colleges, and adjust tradition in the program. Under maintaining curriculum relevant premise, we enlarge the study period intensity of the first six semesters, so all of the professional foundation courses and 
professional elective courses are mainly in the first six semesters, while few compulsory courses and part specialized optional courses in the seventh semester. In the seventh semester, students are encouraged to work in software companies, so that obtain practical work experience as well as opportunities and conditions for employment.

\section{Strengthening Practical Teaching}

The engineering feature of software engineering disciplines emphasizes importance of practice teaching. The practice is the important supply of theories, and provides support and foundation for the theories. It is the important component part of "software engineering". Practice teaching effect and quality of computer professional students have a direct relationship. Practice teaching should cover the major aspects of software engineering, limited targets, operable, easy to carry out.

Through practice activities, students can master basic method, process and the basic tools of software system analysis, design, implementation, testing and maintenance and project management. According to the engineering methods, students can complete the software development task by the role of project team. Through these activities, they will understand software engineering concepts, principles and theories deeply, and their software development skills, team cooperation ability, system design and construction capacity, as well as professional attributes will be cultivated.

For the realization of software engineering educational target, we strengthened specially the practice teaching link in the cultivation plan. Besides the traditional experiment courses, strong comprehensive software design project practice courses are arranged each semester, uninterrupted for four years. Meanwhile, we design carefully eight project courses, including "software engineering practice foundation", "algorithm and programming practice", "information system design and implementation", "software projects comprehensive practice", "innovative design project" and so on, to realize the comprehensive application and integration of core professional theory courses. We arrange more practice credits which ensure students can effectively complete technical knowledge learning and the ability training in the limited teaching time. For example, "software engineering practice foundation" project course drives learning and integration application of the three core courses of "programming foundation", "object-oriented technology" and "software engineering introduction", relating and intertwining theoretical knowledge learning and project practice activities closely, simultaneously requesting the synchronization maintenance between the theory and practice project courses in the progress arrangement. Moreover, we encourage and impel students to carry out various and lively extracurricular practice activities for displaying special and promoting personal value, through setting up innovation credits and innovation practice project elective course.

The new SE-CDIO cultivation plan abandoned tradition of heavy theory knowledge and light practice. The consequence is to cultivate students' innovation consciousness, team cooperation spirit and style of applying theory to reality. Project design courses drive some core courses, which makes students learn more actively, studying with problems, and more with pertinence and effectiveness. The backbone and leading direction of core course cultivation structure is the project courses, and every project practice course drives some professional courses. There are several advantages studying in this way. First, the course plans develop in the way of applying theory to reality, which can promote students' enthusiasm and initiative, make them learn more with pertinence, thus study for application. Second, the project is launched by the association cooperation. Students can cultivate their own team cooperation spirit, team communication skills and system regulation ability through projects. The projects drive learning of core professional knowledge. The project practice causes students to obtain necessary software development experience, improving and cultivating engineering practice ability, synergy ability, and professional attributes comprehensively.

Moreover, in addition to setting "team motivation and communication" as specialized fundamental course independently, we emphasize that software design projects are carried out in team cooperation way, and stress cultivation of team cooperation spirit, communication skills and the system control ability in the process of 
completing projects. It is most important for students to learn to know, to learn to do, to learn to live together, to learn to be, and finally to become higher quality software engineer who has lifelong learning capability.

Students lack understanding to society and enterprise environment, as well as engineering background and actual system development experience. In order to resolve these problems, the institute and the taiji computer company reaches an agreement. Taiji Computer Company provides students with the production practice environment of software engineering. Both sides cooperated have established the practice base. All students in this specialty complete production and practice of software engineering in the base. This is an effective mechanism established, by which students develop the software engineering practice in software factories and the enterprises, and the evaluation mechanism of enterprise participating in student's inspection has been introduced as well. At present, three grade students have practiced in the company, and about $70 \%$ students have obtained the state-level "the black box test certificate, and the outstanding accounts for $15 \%$.

\section{Conclusion}

SE-CDIO mode takes latest achievements in overseas engineering education and benign proposal of the software industry as a foundation. Resting on the CDIO international engineering education idea and the framework, the mode instructs software engineering education teaching reform. According to the request of the CDIO standard and IEEE-SE2004, we establish engineering practice teaching system by adjusting the course system and teaching contents, improving teaching methods and means. Combining software engineering discipline development status and characteristics, we propose the SE-CDIO pattern suitable for software engineers' education and fostering, and have been implementing since 2006. The practice shows that student's programming skill, team cooperation ability have the remarkable enhancement, and that lower grade students had the initial concept and perceptual knowledge to the software engineering, more thicker learning interest, more strenuous self-learning power. We see that the education concept of "learning in doing, doing in learning, doing while learning, learning while doing", makes engineering professional education more effective.

\section{Acknowledgements}

This paper is supported by Beijing Municipal Education and Pedagogy Reform Engineering Project, the Funding Project for Academic Human Resources Development in Institutions of Higher Learning Under the Jurisdiction of Beijing Municipality (PHR200907220), and Characteristic Undergraduate Specialty Construction Fund of Beijing Higher Education.

\section{References}

[1] Edward F. Crawley, Johan Malmqvist, Sören Ostlund, Doris R.Brodeur.Rethinking Engineering Education : The CDIO Approach (M), New York : Springer,2007:1-278

[2] National Academy of Engineerng, The Engineer of 2020: Visions of Engineering in the New Century, Washington, DC: National Academy Press, 2004

[3] Kjersdam, F., and Enemark, S., The Aalborg Experiment -Implementation of Problem Based Learning, Aalborg: Aalborg University Press, 2002.

[4] Downey, G., "Are Engineers Losing Control of Technology? From 'Problem Solving' to 'Problem Definition and Solution' in Engineering Education”,Chemical Engineering Research and Design, Vol. 83, 2005. 